\title{
A clinical study of effect of standard labour protocols on rates of primary caesarean section at a tertiary care centre, Madurai, India
}

\author{
Shanthi C., Mahalakshmi N.K.*
}

Department of Obstetrics and Gynecology, Government Madurai Medical College, Madurai, Tamil Nadu, India

Received: 10 July 2018

Accepted: 02 August 2018

\section{*Correspondence:}

Dr. Mahalakshmi N.K.,

E-mail: mduogs@gmail.com

Copyright: () the author(s), publisher and licensee Medip Academy. This is an open-access article distributed under the terms of the Creative Commons Attribution Non-Commercial License, which permits unrestricted non-commercial use, distribution, and reproduction in any medium, provided the original work is properly cited.

\begin{abstract}
Background: Caesarean section rates are on the rise all over the world. Primary caesarean section usually determines the future obstetric course of any woman and therefore should be avoided whenever possible. WHO recommended that caesarean rates should not be more than $15 \%$. In this view we started our study on how to reduce the rate of Primary caesarean section in Tertiary Care Centre, Madurai, India. The objective of the present study was to evaluate how the implementation of universally acceptable standards affects rates of primary caesarean section rates without compromising maternal and foetal safety

Methods: This a comparative study on the effect of standard labour protocols and guidelines devised after audit of cases from January 2017 to June 2017, on the rate of primary caesarean section rates, induction of labour, failed induction, maternal and fetal outcomes before and after the implementation of the guidelines.

Results: Primary caesarean section rates from $52.85 \%$ to $45.02 \%$ noted in the induced cases. There were no significant adverse maternal and perinatal outcomes.

Conclusions: Implementation of standard labour protocols can reduce primary caesarean section rate without compromising maternal or foetal safety.
\end{abstract}

Keywords: Audit, Implementation of labour, Protocols, Primary Caesarean section,

\section{INTRODUCTION}

Caesarean section can be life saving for the foetus, the mother and both. But higher caesarean section rates are an issue of international public health concern. WHO recommended that caesarean rates should not be more than $15 \%$. Scar over the uterus changes the obstetric future of woman and hence it is necessary to use primary caesarean section judiciously.

In this view, a complete audit cycle of all the primary sections performed in Madurai, government medical college was conducted, and new labour management guidelines were implemented after the first audit.
Strategies implemented for obstetric clinical practice are:

- For postdatism, non-severe preeclampsia, severe preeclampsia without end organ damage: if bishop score is $0,1,2$ - Foley induction is done prior to PGE2 gel. Instead of 6 hours interval, PGE2 gel is repeated after $24 \mathrm{hrs}$ if bishop score is < 4

- $\quad$ Pre-induction and post induction CTG monitoring

- Training and retraining in CTG interpretation in order to reduce the interobserver variation.

- $\quad$ Lung maturity (inj dexamethasone $6 \mathrm{mg} 12^{\text {th }}$ hourly 4 doses prior to 39 weeks) is given.

- Drills in instrumental deliveries to reduce the rate of $2^{\text {nd }}$ stage LSCS. 
- Partograph is plotted for all cases in active phase of labour.

- All government primary health centres are instructed for early referral by training programmes.

- Promoting assisted breech deliveries in multiparous women for spontaneous onset of labour, if there is no contraindication for ABD.

- (Criteria for nonprogress of labour should be fulfilled as follows:

- Nullipara: 6 hours of active labour with no cervical change for 4 hours.

- Multipara: 4 hours of active labour with no cervical change for 2 hours.). ${ }^{1}$

\section{METHODS}

This is a comparative study on the effect of standard labour protocols on the rates of primary caesarean section rates. Sources of data: All primary section cases either primigravida or multigravida in the department of Obstetrics and Gynaecology, Government Medical College, Madurai. Methods of collection of data: Open label, comparative, prospective study. Study period: 6 months

\section{Inclusion criteria}

- Age 18-35,

- All primigravida except major degree CPD

- Except malpresentations

- Except malrotations

- All multiparous women with previous normal labour

- all postdated women with reassuring ctg,

- Preeclampsia

- Eclampsia patients without end organ damage

\section{Exclusion criteria}

- $\quad$ Age $<18$ and $>35$,

- Primi with major CPD,

- Malpresentations,

- Malrotations,

- Non-reassuring CTG

- Preeclampsia

- Eclampsia patients with end organ damage.

\section{RESULTS}

Table 1: Types of deliveries during audit cycle.

\begin{tabular}{|lll|l|}
\hline January to & $\begin{array}{c}\text { April to } \\
\text { June }\end{array}$ & P value \\
\hline $\begin{array}{l}\text { Total } \\
\text { deliveries }\end{array}$ & 1037 & 915 & \\
\hline $\begin{array}{l}\text { Primary } \\
\text { LSCS }\end{array}$ & 600 & 412 & $\begin{array}{l}<0.001 \\
\text { significant }\end{array}$ \\
\hline $\begin{array}{l}\text { Repeat } \\
\text { LSCS }\end{array}$ & 437 & 503 & $\begin{array}{l}<0.001 \\
\text { significant }\end{array}$ \\
\hline
\end{tabular}

Overall caesarean section rates after the implementation of standard labour protocols reduced from $57.85 \%$ to $45.02 \%$ respectively. Approximately $45.02 \%$ of women had primary caesarean which is a significant reduction from $57.85 \%$. There were no adverse maternal and perinatal outcomes. Non-progress of labour and suboptimal Cardiotocography were the two main indications for emergency caesarean sections-soliman et al. whereas breech presentation was the indication commonest for elective sections.

Table 2: Types of LSCS-during the audit cycle.

\begin{tabular}{|llll|}
\hline $\begin{array}{l}\text { Type of } \\
\text { LSCS }\end{array}$ & $\begin{array}{l}\text { January } \\
\text { to march }\end{array}$ & $\begin{array}{l}\text { April to } \\
\text { June }\end{array}$ & p value \\
\hline Elective & 413 & 386 & $\begin{array}{l}0.185 \\
\text { insignificant }\end{array}$ \\
\hline Emergency & 624 & 529 & $\begin{array}{l}0.185 \\
\text { insignificant }\end{array}$ \\
\hline
\end{tabular}

There was objective evidence to justify the need for caesarean section including correctly maintained partograms, proper documentation, well selected cases for induction of labour and hundred percent involvement of senior personnel (consultant level) in decision making.

Table 3: Indications for LSCS during the audit cycle.

\begin{tabular}{|lll|}
\hline Indication for LSCS & $\begin{array}{l}\text { January to } \\
\text { March }\end{array}$ & $\begin{array}{l}\text { April to } \\
\text { June }\end{array}$ \\
\hline Breech & 62 & 43 \\
\hline Obstructed labour & 13 & 10 \\
\hline APH & 18 & 14 \\
\hline Fetal distress & 302 & 186 \\
\hline Failed induction & 62 & 36 \\
\hline Deep transverse arrest & 4 & 6 \\
\hline Cephalopelvic disproportion & 262 & 51 \\
\hline Ap eclampsia & 14 & 12 \\
\hline Severe preeclampsia & 16 & 13 \\
\hline IUGR with doppler changes & 17 & 17 \\
\hline Long period of infertility & 44 & 36 \\
\hline
\end{tabular}

Table 4: NICU admissions during the audit cycle.

\begin{tabular}{|c|c|c|c|}
\hline & $\begin{array}{l}\text { January } \\
\text { to March }\end{array}$ & $\begin{array}{l}\text { April } \\
\text { to June }\end{array}$ & P value \\
\hline $\begin{array}{l}\text { NICU } \\
\text { admissions }\end{array}$ & 984 & 710 & $\begin{array}{l}<0.001 \\
\text { significant }\end{array}$ \\
\hline
\end{tabular}

Assessment of maternal outcome was made on the need for high dependency unit monitoring and number of postoperative complications. large number women shifted to HDU for observation due to an underlying medical condition were signed out to the ward within 24 to 48 hours of the delivery.

There was no difference in the rate of postoperative complications including puerperal pyrexia, wound infection and postpartum haemorrhage. 


\section{DISCUSSION}

Can caesarean section rates be safely reduced? our audit was conducted with the objective to answer this question. A single cut off for defining a high or an ideal caesarean section rate (CSR) is very difficult as it may vary in different maternity units according to the clinical practice and setup. In 1985, world health organization had suggested that there were no additional health benefits associated with a caesarean section rate above 10-15\% acceptable rates for caesarean sections were determined by departmental consensus, keeping RCOG guidelines in mind. We shared the results of our audit with all the consultant obstetricians working in our unit and implemented the acceptable strategies. This step proved to be fruitful at the end of the audit cycle and resulted in a marked improvement in the quality of obstetric care, reduction in the number of primary caesarean sections and more justified indications for induction of labour. Robson et al reported an overall decrease in the caesarean section rates successfully by applying principles of early diagnosis and treatment of dystocia in multiparous women. ${ }^{1,2}$ Despite a significant reduction in the number of primary caesarean sections, we failed to reach the proposed benchmark. The lower effect on the overall caesarean section rate (CSR) is possibly related to large number of elective caesarean sections performed on patients informed choice in the case of one previous caesarean and breech presentation. Soliman et al have reported labour induction as the most important predictor of primary caesarean section. ${ }^{3}$ Literature supports the routine induction of labour at 41 weeks in uncomplicated pregnancies. ${ }^{4,5}$ After changing our policy for postdate inductions to 41 weeks, there was a significant reduction in the number of induced cases with poor bishops score.

Majority of women presented in spontaneous labour resulting in prevention of unnecessary emergency caesarean sections. Aim of modifications in obstetric care management should not jeopardize maternal and foetal safety. Gleishcer et al report safe lowering of caesarean section rate with no increase in maternal and perinatal morbidity and mortality. ${ }^{6-8}$ In present study, there was no adverse effect of the introduced strategies on the maternal and perinatal outcomes and the number of high dependency units' admissions postoperatively. Almost all of these women had underlying medical problems and were transferred electively to the HDU for observation and monitoring. Perinatal outcome was also favourable without any perinatal death and fewer NICU admissions. To conclude safe lowering of the rate of primary caesarean sections is possible without compromising maternal and perinatal outcomes. we strongly recommend the introduction of evidence-based strategies to reduce the number of primary sections on a national level rather than on an individual basis as a first step towards safe motherhood. ${ }^{9,10}$

\section{CONCLUSION}

Implementation of standard labour management strategies can reduce primary caesarean section rates without compromising maternal or foetal safety.

\section{Funding: No funding sources}

Conflict of interest: None declared

Ethical approval: The study was approved by the Institutional Ethics Committee

\section{REFERENCES}

1. Kazmi T, Sarva Saiseema V, Khan S. Analysis of Cesarean section rate-according to Robson's 10-group classification. Oman Med J. 2012;27(5):415-7.

2. Tanaka K, Mahomed K. The ten-group robson classification: a single centre approach identifying strategies to optimise caesarean section rates. Obstetrics Gynecol Int. 2017;2017.

3. Yadav RG, Maitra N. Examining cesarean delivery rates using the Robson's ten-group classification. J Obstet Gynecol India. 2016;66(1):1-6.

4. Caughey AB, Cahill AG, Guise JM, Rouse DJ, American College of Obstetricians and Gynecologists. Safe prevention of the primary cesarean delivery. American journal of obstetrics and gynecology. 2014;210(3):179-93.

5. Patar Jagannath,Malakar Himangshu,Pronamika konyak, Balsrich Marak, Ishaa Goel Primary caesarean section in primigravida : a clinical study Sch J App Med Sci. 2016:4(9B);3307-11.

6. Sanchez-Ramos L, Kaunitz AM, Peterson HB, Martinez-Schnell B, Thompson RJ. Reducing cesarean sections at a teaching hospital. American $\mathrm{J}$ Obstet Gynecol. 1990;163(3):1081-8.

7. Myers SA, Gleicher N. A successful program to lower cesarean-section rates. New Eng J Med. 1988;319(23):1511-6.

8. Socol ML, Garcia PM, Peaceman AM, Dooley SL. Reducing cesarean births at a primarily private university hospital. Am J Obstet Gynecol. 1993;168(6):1748-58.

9. Bickell NA, Zdeb MS, Applegate MS, Roohan PJ, Siu AL. Effect of external peer review on cesarean delivery rates: a statewide program. Obstet Gynecol. 1996;87(5):664-7.

10. Somprasit C, Tanprasertkul C, Kamudhamas A. Reducing caesarean delivery rates: an active management labour program. J Med Assoc Thai.2005;88(1):20-5.

Cite this article as: Shanthi C, Mahalakshmi NK. A clinical study of effect of standard labour protocols on rates of primary caesarean section at a tertiary care centre, Madurai, India. Int J Reprod Contracept Obstet Gynecol 2018;7:3766-8. 